fell off she re-cemented them herself with superglue. She was prompted to seek treatment as the layers of glue $h$ ad become so thick that it was no longer effective and her poor appearance was causing her great distress, impacting adversely on her rehabilitation into society, and had increased her dental phobia.

Further investigation also revealed multiple deep carious lesions with potential pulpal involvement, a diet history of excessive sugar intake, including six spoonfuls of sugar in her tea, and the fact that she was in the early stages of pregnancy, ruling out the use of sedation to manage her dental anxiety.

Whilst a dentist cannot accurately predict the future potential health and personal issues that their patients may suffer from, we feel that before 'cosmetic procedures' are undertaken one should always consider what the consequence would be if treatment fails or the patient becomes unable to maintain it both financially and psychologically.

This case highlights the importance of a thorough social and medical history with a full caries risk assessment prior to any cosmetic treatment planning. We are now facing the challenge of achieving oral health for this patient who is currently very vulnerable and is under a great deal of stress, partly as a result of this failed 'smile design'.

C. Chan, C. Colhoun, D. Simons

London

DOI: 10.1038/sj.bdj.2012.623

\section{DEVELOPED AND REFINED}

Sir, in response to the letter published in the $B D J$ in April titled Inevitable deskilling (BDJ 2012; 212: 303), we wish to challenge Mr Marlow's assumption that frequent referral of 'even the most straightforward of extractions' is likely due to shortcomings of the nation's dental schools.

We are current 3rd year students (first clinical year) at Newcastle University, School of Dental Science and we believe that our training in routine extractions is first class.

In our first year of hands-on dentistry we have already had four weeks of oral surgery attachments. This allows us to have an intense experience of purely dental extractions alongside excellent clinical supervision and ample nursing support. This has I believe given us tremendous experience in managing most extractions and even simple dento-alveolar surgery.

This initial experience is built on with further block allocations to the oral surgery clinics of four weeks in 4th year and three weeks in final year. Continual allocation to our dental emergency clinic means our skills are always being developed and refined. Our competence is assessed in molar extractions, root removal and surgical removal of teeth, and student evaluation of the oral surgery course is consistently excellent.

Whilst we cannot speak for other undergraduate courses we believe that our training at Newcastle provides us with competence and confidence to undertake routine extractions and moreover deal with simple dentoalveolar surgical procedures provided foundation dental training practices are appropriately equipped and the trainers are happy for surgical extractions to occur.

\section{G. Garlington, F. Usher} Newcastle DOI: 10.1038/sj.bdj.2012.624

\section{A LOGICAL SERVICE}

Sir, Martin Kelleher (BDJ 2012; 212:

365-367) succinctly points out the ethical merits of obtaining informed consent from our patients prior to elective restorative therapy, although I am sure that such ethics have long been established by the GDC.

I would like to be able to quote accurate outcome success rates for the various dental procedures that we, as general dental practitioners, carry out on a daily basis.

Indeed, prior to 2006, the Business Services Authority (then the Dental Practice Board) probably held the most meaningful data.

It would therefore be a logical service to the profession if such data were available to us via a website so as to enable us to obtain informed consent.
In addition, a centrally updated database of evidence based papers (eg NICE) would enable the 'wet-fingered dentist' to give patients the outcome figures advocated by the author.

\section{N. Larah}

Manchester

DOI: 10.1038/sj.bdj.2012.625

\section{SHOULD BE CREDITED}

Sir, I write further to the letter Historical fraud? (BDJ 2012; 212: 573). In 1864 the American Dental Association acknowledged that Horace Wells should be credited with the introduction of inhalation anaesthesia having used nitrous oxide for dental extraction in 1844. In 1870 this was also acknowledged by the American Medical Association. The event was commemorated by the American Dental Association in $1948 .{ }^{1}$

There were others who claimed to have discovered anaesthesia, for example a Dr Crawford Long of Jefferson, Georgia, had claimed to have removed a neck tumour with ether anaesthetic in 1842, before Morton had used ether. However, publication and knowledge of this was not revealed until some years after the use of ether had been generally accepted.

The fascinating story of the discovery of anaesthesia and the attempts by Morton to capitalise on it is beautifully told in The sleep of life - a novel by Richard Gordon, 1975. The book is out of print but there are numerous copies for sale at online book sellers.

A. Sadler

By email

1. Gies WJ (ed). Horace Wells, dentist. Father of surgical anesthesia. Proceedings of centenary commemorations of Wells' discovery in 1844 and list of Wells Memorabilia including bibliographies, memorials and testimonials. American Dental Association, 1948.

DOI: $10.1038 /$ sj.bdj.2012.626

The $B D J$ website now includes a facility enabling readers to immediately comment on letters. All comments must comply with the nature. com Terms and Conditions and Community Guidelines - visit the $B D J$ website to find out more and to post your comment. 